\title{
Multifactorial determinants that govern nanoparticle uptake by human endothelial cells under flow
}

This article was published in the following Dove Press journal:

International Journal of Nanomedicine

13 June 2012

Number of times this article has been viewed

\author{
Stephen Paul Samuel ${ }^{1, *}$ \\ Namrata Jain ${ }^{1, *}$ \\ Frank O'Dowd ${ }^{2}$ \\ Toby Paul ${ }^{2}$ \\ Dmitry Kashanin ${ }^{2}$ \\ Valerie A Gerard ${ }^{3}$ \\ Yurii K Gun'ko ${ }^{3}$ \\ Adriele Prina-Mello 1,4 \\ Yuri Volkov ${ }^{1,4}$ \\ 'Department of Clinical Medicine, \\ Institute of Molecular Medicine, \\ ${ }^{2}$ Cellix Ltd, Longmile Business Centre, \\ ${ }^{3}$ School of Chemistry, ${ }^{4}$ Centre for \\ Research on Adaptive Nanostructures \\ and Nanodevices, Trinity College \\ Dublin, Dublin, Ireland \\ *These authors contributed equally \\ to this work
}

Correspondence: Adriele Prina-Mello Rm 078, Institute of Molecular Medicine, James's Street, Dublin 8, Ireland

Tel +0 I I 353 । 8963259

Fax +0 I I 353 | 4542043

Email prinamea@tcd.ie
Abstract: Vascular endothelium is a potential target for therapeutic intervention in diverse pathological processes, including inflammation, atherosclerosis, and thrombosis. By virtue of their intravascular topography, endothelial cells are exposed to dynamically changing mechanical forces that are generated by blood flow. In the present study, we investigated the interactions of negatively charged $2.7 \mathrm{~nm}$ and $4.7 \mathrm{~nm}$ CdTe quantum dots and $50 \mathrm{~nm}$ silica particles with cultured endothelial cells under regulated shear stress (SS) conditions. Cultured cells within the engineered microfluidic channels were exposed to nanoparticles under static condition or under low, medium, and high SS rates $(0.05,0.1$, and $0.5 \mathrm{~Pa}$, respectively). Vascular inflammation and associated endothelial damage were simulated by treatment with tumor necrosis factor- $\alpha$ (TNF- $\alpha)$ or by compromising the cell membrane with the use of low Triton X-100 concentration. Our results demonstrate that SS is critical for nanoparticle uptake by endothelial cells. Maximal uptake was registered at the SS rate of $0.05 \mathrm{~Pa}$. By contrast, endothelial exposure to mild detergents or TNF- $\alpha$ treatment had no significant effect on nanoparticle uptake. Atomic force microscopy demonstrated the increased formation of actin-based cytoskeletal structures, including stress fibers and membrane ruffles, which have been associated with nanoparticle endocytosis. In conclusion, the combinatorial effects of SS rates, vascular endothelial conditions, and nanoparticle physical and chemical properties must be taken into account for the successful design of nanoparticle-drug conjugates intended for parenteral delivery.

Keywords: endothelium, shear stress, quantum dots, membrane ruffling, stress fibers, atomic force microscopy, microfluidics

Nanoparticle (NP) technologies are significantly affecting the development of both therapeutic and diagnostic agents. Although enormous progress in the field of nanotechnology has been achieved, basic discoveries have not yet translated into effective targeted therapies. NPs can potentially improve the pharmacokinetics and pharmacodynamics of drugs; however, the complexity of in vivo systems imposes multiple barriers that severely inhibit efficiency, which must be overcome to fully exploit the theoretical potential of NPs. Endothelial cells (ECs) that line the interior of the entire vascular system represent a major barrier for therapeutic agents traveling from the bloodstream to the target tissues. Recent studies have focused on targeting the endothelium with NPs as therapeutic agents for a variety of pathological conditions in the vascular system because of the large population of ECs and their proximity to the blood flow.

ECs in vivo are exposed to a variety of hemodynamic forces that are created by blood flow and by the pulse wave dictated by the cardiac cycle. Shear stress (SS) is the dragging mechanical force that acts at the interface between flowing blood and 
the vessel wall. ECs recognize SS as a mechanical stimulus, and the ECs then transmit the signal into the interior of the cells, thereby triggering a variety of cellular responses that involve alterations in cell morphology, cell function, and gene expression. ${ }^{1}$ The ability of ECs to sense a flow stimulus is the earliest stage in the process of SS-induced mechanotransduction, and it is a prerequisite to downstream cellular responses. A variety of cell-membrane molecules and microdomains - including ion channels, G proteins, growth factor receptors, tyrosine kinase receptors, adhesive proteins, caveolae, the cytoskeleton, the glycocalyx, and the primary cilia - are involved in SS-induced signal transduction pathways. ${ }^{2}$ ECs both in vivo and in vitro respond to SS by reorganizing F-actin into thick bundles of stress fibers that are aligned in the direction of the flow. ${ }^{3-5}$ The cytoskeletal reorganization in response to flow is associated with an increase in cell stiffness, ${ }^{6}$ and it plays an important role in SS-induced gene expression by ECs. ${ }^{7-9}$ Moreover, ECs regulate leukocyte adhesion as well as the migration of monocytes and leukocytes into the blood vessel wall via the secretion of chemotactic factors and the expression of selectins (ie, types E, L, and P) and other cell-adhesion molecules (ie, platelet/EC adhesion molecule [PECAM], vascular cell adhesion molecule [VCAM], and intercellular adhesion molecule [ICAM] $).{ }^{10}$ For example, P-selectin that is expressed on activated ECs interacts with the glycoprotein Ib $\alpha$ of blood platelets. A study of the conjugation of $100 \mathrm{~nm}$ polystyrene NPs with glycocalicin (ie, the extracellular segment of glycoprotein Ib $\alpha$ ) demonstrated that the substance mimicked platelets, thereby significantly increasing particle adhesion on P-selectin-coated surfaces as well as the cellular uptake of NP by activated ECs under physiological flow conditions. ${ }^{11}$ In addition, poly-(lactic-co-glycolic acid) microspheres cofunctionalized with a selectin ligand and an antibody against ICAM-1 have been used for the leukocyte-mimetic targeting of endothelium. ${ }^{12}$ Based on the importance of SS to EC function and integrity, it is likely that the mechanoreceptors activate intracellular signaling pathways to influence the complete endothelial response to SS. ${ }^{13}$ Interestingly, in humans, the mean SS varies between 0.05 and $0.76 \mathrm{~Pa}$ in the veins, 0.3 and $0.7 \mathrm{~Pa}$ in the peripheral arteries (eg, the brachial artery, the femoral artery), and 1.0 and $1.5 \mathrm{~Pa}$ in the central arteries (eg, the carotid artery). ${ }^{14-18}$ Due to the ubiquitous presence of endothelium in the blood vessels of all calibers, the constant exposure of these cells to SS, and their sensitivity to interaction with other celladhesion molecules, vascular endothelium could be targeted for systemically administered NP-based therapies. ${ }^{12,19}$
There are different classes of NP available for biomedical applications. Inorganic, biocompatible, porous ceramic NPs (eg, $\mathrm{SiO}_{2}$ ) can be used for cancer therapy. ${ }^{20}$ Properties associated with these NPs - such as water dispersity, resistance to microbial attack and swelling, and easily modifiable surfaces - make them attractive candidates for nanomedicine applications. However, these particles are not biodegradable, and they can accumulate inside the cells. Another class of NPs is presented by semiconductor quantum dots (QDs), which possess unique optoelectronic properties such as tunable narrow emission spectra, high quantum yields, broad absorption spectra, and high resistance to photobleaching. ${ }^{21}$ QDs are successfully used in biomedicine as labeling agents for imaging biological molecules, cells, and even tissues ${ }^{22}$ or to trace drug molecules in live organisms. ${ }^{23,24}$ However, for biological applications, QDs must be surface passivated with other materials to allow for dispersion and to prevent the leakage of toxic heavy metals. ${ }^{25}$ There is evidence that both negatively ${ }^{26}$ and positively ${ }^{27,28}$ charged QDs can be endocytosed and even penetrate nuclei. ${ }^{29}$ A systematic study of the mechanisms of interaction of nonfunctionalized CdTe and CdSe/ZnS QDs with a panel of live human cells of different origin has demonstrated that the nonfunctionalized QDs exploit the cell's active transport machineries for intranuclear delivery. ${ }^{30}$ The effects of NPs such as carbon black, ${ }^{31}$ silver, ${ }^{32}$ metal oxides, ${ }^{33} \mathrm{MgO},{ }^{34} \mathrm{SiO}_{2},{ }^{35} \mathrm{QDs}^{21}$ and polymeric $\mathrm{NPs}^{19}$ on ECs have been studied under static conditions. However, no comprehensive study has been undertaken to evaluate the interaction of engineered NPs on human ECs under varying flow conditions.

Therefore, in the present study, we investigated the interactions of negatively charged $\mathrm{CdTe}-\mathrm{QD}$ and fluorescent $\mathrm{SiO}_{2}-\mathrm{NPs}$ on human umbilical vein ECs (HUVECs) under controlled SS rates using a microfluidic platform (Cellix Ltd, Dublin, Ireland). Immunofluorescence studies demonstrated the uptake of NP in HUVECs that were exposed to SS. High content analysis was used to quantify the cellular uptake of NPs and to analyze the effect of NPs on cell proliferation. In addition, atomic force microscopy (AFM) showed the combinatorial effects of SS and NPs on HUVEC morphology, such as membrane ruffling (ie, a meshwork of newly polymerized actin filaments) and the development of stress fibers. For the first time, we demonstrate that SS-induced membrane ruffling further mediates the uptake of QDs and $\mathrm{SiO}_{2}$-NPs in human ECs.

\section{Materials and methods Chemicals and materials}

Negatively charged CdTe-QDs were synthesized and characterized in the Department of Chemistry at Trinity 
College Dublin, as described previously. ${ }^{36}$ Fluorescent $\mathrm{SiO}_{2}$-NPs (Product no Z-PS-SIL-RFP-0,05) were purchased from Postnova Analytics GmbH (Landsberg, Germany). All reagents were purchased from Sigma-Aldrich (St Louis, MO). Dulbecco's Modified Eagle's Medium, fetal bovine serum, gentamicin, and amphotericin B were from Gibco (Invitrogen Ltd, Carlsbad, CA). All plastic wares were from Nunc (Thermo Fisher Scientific, Waltham, MA).

Three batches of CdTe-QDs that were emitting in the green part of the spectrum were used; these are hereinafter referred to as $Q D 2.7$. Three batches of CdTe-QDs emitting in the red part of the spectrum were used; these are hereinafter referred to as $Q D 4.7$. A fully characterized batch of rhodamine-B-loaded $\mathrm{SiO}_{2}$-NPs emitting in the red part of the spectrum were used; these are hereinafter referred to as NP50. Transmission electron microscopy (TEM) of the three NPs was carried out to investigate particle size, geometry, and dispersion (Figure 1). TEM imaging and measurement were performed on at least 100 NPs at the Advanced Microscopy Laboratory (CRANN) at Trinity College, Dublin with the use of a TEM Titan instrument (FEI Ltd, Hillsboro, OR). QDs and $\mathrm{SiO}_{2}$-NPs were mounted on $\mathrm{Cu}$ lacey carbon-coated TEM grids and imaged at $300 \mathrm{kV}$.

Properties of the two QDs and the $\mathrm{SiO}_{2}-\mathrm{NPs}$ used are summarized in Table 1.

\section{Cell culture}

A HUVEC line (ATCC CRL-1730) was acquired from ATCC-LGC Standards (Middlesex, UK). Cells were cultured in Dulbecco's Modified Eagle's Medium supplemented with $10 \%(\mathrm{v} / \mathrm{v})$ fetal bovine serum (10\%), gentamicin $(0.5 \%)$, and amphotericin $\mathrm{B}(1 \%)$ at $37^{\circ} \mathrm{C}$ in a humidified atmosphere containing $5 \%$ carbon dioxide.

\section{Regulated shear stress assays}

The VenaFlux ${ }^{\mathrm{TM}}$ Platform (Cellix Ltd) was used to carry out the in vitro assays that mimicked the flow conditions of blood vessels. ${ }^{37-40}$ VenaEC $^{\mathrm{TM}}$ Biochips were used to investigate the uptake and localization of NPs under controlled SS. These biochips contain substrates treated with tissue culture that enable the seeding and culturing of EC. The optically transparent polydimethylsiloxane chips, which are comprised of two half-open channels, were then clamped on top of EC monolayers with microscope-mounted frames. This created two parallel channels, which imitate human microcapillaries as shown in the supplementary information (Figure S1). NPs suspended in phosphate-buffered saline (PBS) were injected through the channels using the Mirus ${ }^{\mathrm{TM}}$ Nanopump (Cellix Ltd) and the FlowAssay ${ }^{\mathrm{TM}}$ software (Cellix Ltd), which supports a range of SSs for dynamic-flow-based assays, with the pressure applied ranging from 0.1 to $10 \mathrm{dynes} / \mathrm{cm}^{2}$ (ie, industrial and CGS equivalent) or from 0.01 to 1 pascal (ie, IU equivalent), respectively. This allowed for the mean velocity profile calculation within the biochip during each experiment, which was calculated as $v_{\text {mean }}=Q /(w h)$ where $Q$ is the volumetric flow rate, $w$ is the biochip elliptical crosssection width ( $w=400 \mu \mathrm{m})$, and $h$ is the height $(h=100 \mu \mathrm{m})$. The shear rate, $\gamma$, in the middle of the biochip rectangular cross section, was calculated by using $\gamma=6 v_{\text {mean }} / h$. The SS was then determined by the equation $\tau=6 v_{\text {mean }} \eta / h$, where $\eta$ is the dynamic viscosity measured at a certain temperature $\left(\mathrm{T}=37^{\circ} \mathrm{C}, \mathrm{T}_{\text {bin }}=2^{\circ} \mathrm{C}\right)$.

\section{Evaluation of nanoparticle uptake by human umbilical vein endothelial cells}

The HUVECs were seeded on $0.2 \%$ gelatin-coated acrylic substrates (Cellix Ltd) at a concentration of $4.33 \times 10^{5}$ cells per substrate and allowed to settle and grow for 24 hours. Before the start of the experiments, the nuclei were stained with Hoechst (1:1000 from stock of $1 \mathrm{mg} / \mathrm{mL}$ ) for 5 minutes. After washing the cells with medium, endothelial monolayers (normal or supplemented with tumor necrosis factor- [TNF- $\alpha$ ] at $10 \mathrm{ng} / \mathrm{mL}$ for 12 hours) were exposed to QD2.7, QD4.7, or NP50 suspended in PBS under low, medium, and high SS rates $(0.05,0.10$, and $0.50 \mathrm{~Pa}$, respectively) for 20 minutes using
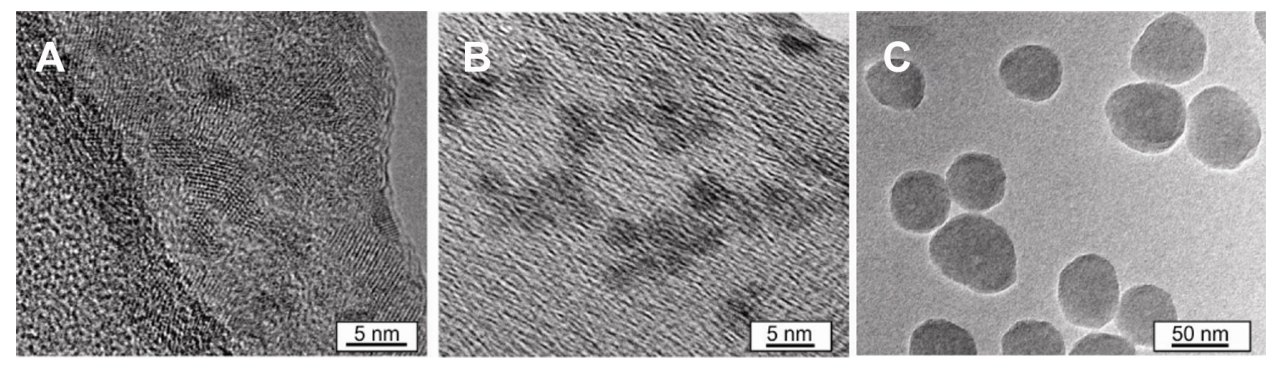

Figure I Transmission electron micrographs of nanoparticles. (A) $2.7 \mathrm{~nm}$ quantum dots. (B) $4.7 \mathrm{~nm}$ quantum dots. (C) $50 \mathrm{~nm} \mathrm{SiO}{ }_{2}$ nanoparticles. 
Table I Properties of quantum dots and silica nanoparticles used in the present experiments

\begin{tabular}{|c|c|c|c|}
\hline Nanoparticles & QD2.7 & QD4.7 & NP50 \\
\hline Size $(\mathrm{nm})$ & $2.70 \pm 0.10$ & $4.70 \pm 0.10$ & $50.00 \pm 0.50$ \\
\hline Core chemical structure & $\mathrm{CdTe}$ & $\mathrm{CdTe}$ & $\mathrm{SiO}_{2}$ \\
\hline Shell/ligand/dye & TGA & TGA & Rhodamine B \\
\hline Stock concentration $(\mu \mathrm{M})$ & 56.50 & 142.00 & 411.00 \\
\hline Working concentration $(\mu \mathrm{M})$ & $3.00 \pm 0.30$ & $3.00 \pm 0.30$ & $3.00 \pm 0.30$ \\
\hline Zeta potential $(\mathrm{mV})$ & $-26 \pm 7$ & $-47 \pm 13$ & $-42 \pm 5$ \\
\hline $\begin{array}{l}\text { Peak excitation } \\
\text { wavelength }(\mathrm{nm})\end{array}$ & $524 \pm 6$ & $589 \pm 11$ & $569 \pm 10$ \\
\hline $\begin{array}{l}\text { Peak emission } \\
\text { wavelength }(\mathrm{nm})\end{array}$ & $553 \pm 8$ & $622 \pm 11$ & $585 \pm 10$ \\
\hline Quantum yield (\%) & $22 \pm 3$ & $23 \pm 6$ & N/A \\
\hline Solvent & Water & Water & Water \\
\hline
\end{tabular}

Abbreviations: N/A, not applicable; TGA, thioglycolic acid.

a Mirus ${ }^{\mathrm{TM}}$ Nanopump. Live images of ECs were taken with a $20 \times$ objective lens from at least three fields in each channel. Images were computationally integrated with the use of IN Cell Translator Software to a high content analysis platform (GE Healthcare, Hertfordshire, UK). The NP uptake in the HUVECs was then quantified using IN Cell Investigator Software (GE Healthcare). ${ }^{41}$

\section{Imaging nanoparticle cellular localization}

We found that the uptake of QD2.7, QD4.7, and NP50 by HUVECs was maximal at $0.05 \mathrm{~Pa}$. Therefore, the same SS was used in the experiments that were performed to characterize NP localization. For these experiments, cells were seeded on $0.2 \%$ gelatin-coated acrylic substrates (Cellix Ltd) at a concentration of $4.33 \times 10^{5}$ cells per substrate. After 24 hours, the cells were treated with $0.001 \%$ Triton $\mathrm{X}$ for 1 hour or fixed and permeabilized with $0.5 \%$ Triton $\mathrm{X}$ over the course of 3 minutes. Cells were then exposed to QD2.7, QD4.7, or NP50 suspended in PBS for 20 minutes at the medium SS rate (ie, $0.05 \mathrm{~Pa}$ ). ECs that were exposed to QD2.7, QD4.7, or NP50 under static conditions were used as controls. After exposure to NPs, cells were fixed with 3\% paraformaldehyde for 30 minutes at $22^{\circ} \mathrm{C}$. After triple washing the cells with PBS, the cells were stained with either Alexa Fluor $^{\circledR} 546$ phalloidin actin or Alexa Fluor ${ }^{\circledR} 488$ phalloidin actin (1:200 dilution; Invitrogen Ltd) and Hoechst (1:800 of $1 \mu \mathrm{g} / \mathrm{mL}$ stock; Thermo Fisher Scientific) for 1 hour. Acrylic substrates were then mounted onto glass slides and mounted with cover slips. The slides were analyzed by confocal microscopy using the Zeiss LSM 510 Meta system (Carl Zeiss, Jena, Germany), with a $63 \times$ oil immersion objective and a 1.4 numerical aperture. The samples were excited at $488 \mathrm{~nm}$ and $561 \mathrm{~nm}$ laser wavelengths and imaged with emission with band pass filter of 505-550 $\mathrm{nm}$ and long pass filter of $575 \mathrm{~nm}$, respectively.

\section{Analysis of human umbilical vein endothelial cell morphology}

We used AFM to image the surface topography of fixed ECs after they had been subjected to SS, and confocal microscopy was used to visualize the actin cytoskeleton. The HUVECs were seeded on $0.2 \%$ gelatin-coated acrylic substrates (Cellix Ltd) at a density of $8.5 \times 10^{4}$ cells per substrate. After 24 hours, the cells were exposed to an $\mathrm{SS}$ of $0.05 \mathrm{~Pa}$. Cells that were not exposed to flow were considered to be control cells. Cells were then fixed with $3 \%$ paraformaldehyde for confocal microscopy or $2.5 \%$ glutaraldehyde for AFM for 30 minutes at $37^{\circ} \mathrm{C}$. The samples were washed with PBS three times. The cells on the chips were stained with Alexa Fluor ${ }^{\circledR} 546$ phalloidin actin or Alexa Fluor ${ }^{\circledR} 488$ phalloidin actin (1:200 dilution) and Hoechst (1:800 of $1 \mu \mathrm{g} / \mathrm{mL}$ stock) for 1 hour for confocal microscopy studies. For AFM studies, the cells were left in PBS for liquid-phase imaging. AFM measurements were performed on the NTEGRA Spectra system (NT-MDT, Moscow, Russia) in the liquid phase (eg, in PBS) with the use of a tapping mode. The cantilevers used were MLCT (Veeco; Bruker, Billerica, MA), with a typical spring constant of $0.03 \mathrm{~N} / \mathrm{m}$, a resonance frequency of $30 \mathrm{kHz}$ in liquid, and a tip curvature radius of $20 \mathrm{~nm}$. Images were acquired with a resolution of $512 \times 512$ pixels and a scan rate of $0.4 \mathrm{~Hz}$.

\section{High content analysis assay}

A high content analysis platform was used to investigate the SS-independent impact of QD2.7, QD4.7, or NP50 on HUVEC growth. The HUVECs were seeded in 96-well plates (ie, 2000 cells/well) and treated with the indicated concentrations of NPs or QDs for 20 minutes, 4 hours, 8 hours, or 24 hours at $37^{\circ} \mathrm{C}$. Untreated cells were considered to be negative controls. Cells were also treated with positively charged CdTe-QDs as an additional comparative control as a result of the previously reported high-level toxicity of positively charged nanoconstructs on HUVECs. ${ }^{42}$ The cells were washed with PBS, fixed with $3 \%$ paraformaldehyde, and fluorescently stained with Alexa Fluor ${ }^{\circledR} 488$ phalloidin or Alexa Fluor ${ }^{\circledR} 546$ phalloidin to visualize the actin cytoskeletal morphology and then with Hoechst to visualize the nuclei. Five randomly selected fields/wells were scanned from each plate and analyzed with the use of an IN Cell Analyzer 1000 automated microscope (GE Healthcare). 


\section{Statistics}

Results are expressed as the mean \pm the standard error of the mean of at least three independent experiments. Comparisons among the groups' $P$ values were calculated with the use of the two-tail unpaired Student's $t$-test, unless indicated. Data were analyzed and plotted using Excel from the Office suite of programs (Microsoft, Redmond, WA) and GraphPad Prism 5 (GraphPad Software Inc, La Jolla, CA). Statistical significance was considered when $P<0.05$.

\section{Results}

\section{Effect of nanoparticles on endothelial cell proliferation}

When NPs enter the bloodstream after inhalation or injection, it is inevitable that ECs come into direct contact with these particles. Therefore, to examine the effect of NPs on the proliferation of vascular endothelium, cultured HUVECs were treated with QD2.7, QD4.7, or NP50 for up to 24 hours, and cell proliferation was evaluated with the use of high content analysis.

NP50 did not cause any cytotoxic effect on cultured HUVECs after 24 hours of exposure (Figure 2A-D).
By contrast, a significant reduction in the number of cells was observed at all time points (ie, 20 minutes, 4 hours, 8 hours, and 24 hours) after the QD4.7 treatment (Figure 2A-D). QD2.7 was well tolerated for up to 4 hours (Figure 2B). However, a significant reduction in the number of cells was detected at 8 hours (Figure 2C) and 24 hours (Figure 2D).

\section{Shear stress regulates the uptake of nanoparticles by endothelial cells}

We found that the uptake of QD2.7, QD4.7, and NP50 by inactivated HUVECs was significantly lower at $0.5 \mathrm{~Pa}$ as compared with $0.05 \mathrm{~Pa}$ (Figure 3), whereas, in activated HUVECs, a substantial decrease in the uptake of QD2.7 was observed at $0.1 \mathrm{~Pa}$ and $0.5 \mathrm{~Pa}$. By contrast, there was no statistical difference in the uptake of QD4.7 and NP50 among the applied SS rates. Similarly, both QD and NP uptake were not influenced by HUVEC activation at all of the SS rates that were applied. Furthermore, negatively charged QDs and NPs did not show any cellular uptake under static (ie, $0 \mathrm{~Pa}$ ) conditions; there were only low values of background fluorescence.

\section{A}

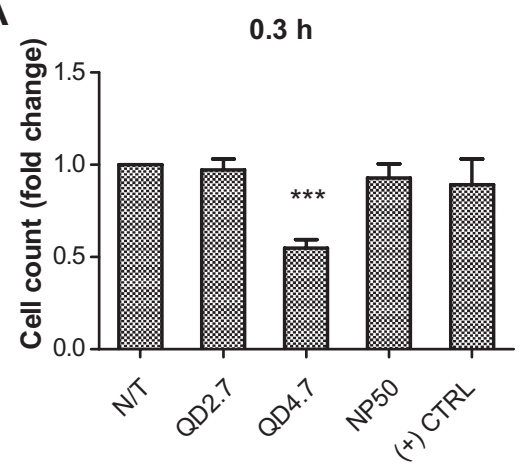

C

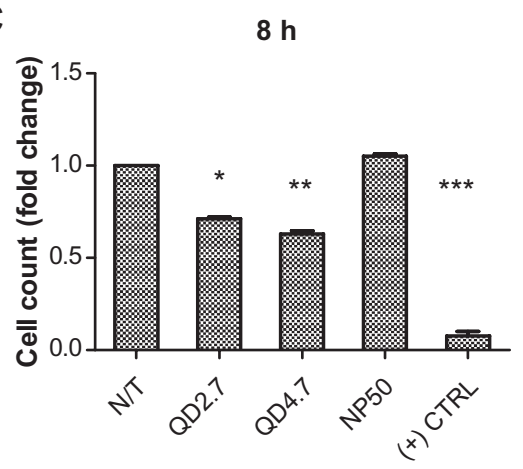

B

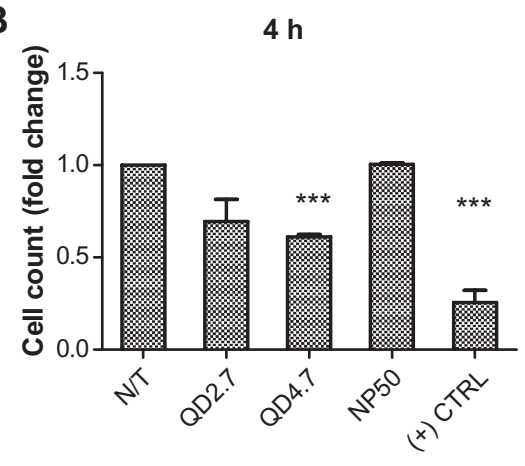

D

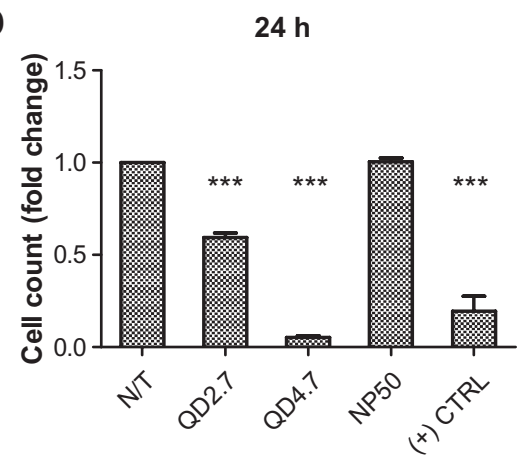

Figure 2 High content analysis to determine the cytotoxic effects of nanoparticles on human umbilical vein endothelial cells. Cells grown in 96 -well plates were treated with or without (N/T) negatively charged QD2.7, QD4.7, or NP50 or with positively charged QD ([+] CTRL) for (A) 20 minutes, (B) 4 hours, (C) 8 hours, or (D) 24 hours and then fixed with $3 \%$ formaldehyde.

Notes: Cells were stained with Hoechst to visualize the nuclei and rhodamine phalloidin to visualize the cell morphology. Images were acquired with the use of an IN Cell Analyzer automated microscope, and cell populations were automatically quantified with the use of IN Cell Investigator Software. Data are given as the fold change in the cell number as compared with untreated control cells from three independent experiments performed in triplicate. $* P<0.05$; $* * P<0.01$; $* * * P<0.00 \mathrm{I}$.

Abbreviation: QD, quantum $\operatorname{dot}(\mathrm{s})$. 


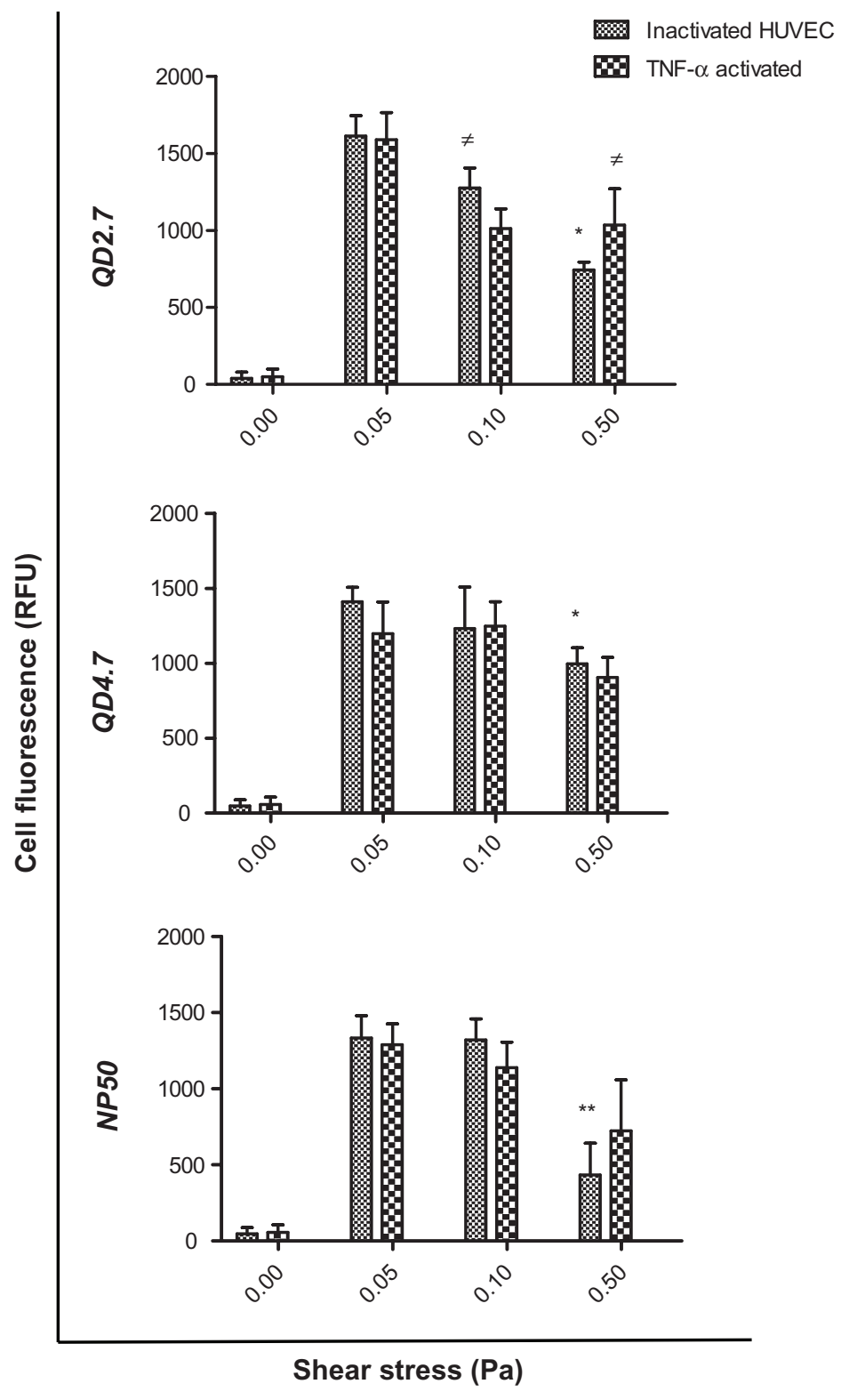

Figure 3 Uptake of CdTe-QD and NP50 by human umbilical vein endothelial cells (HUVEC) under controlled shear stress conditions. Notes: Cell monolayers were exposed under a constant pressure of $0,0.05,0.1$, or 0.5 Pa with negatively charged QD2.7, QD4.7, or NP50 for 20 minutes. The cellular uptake of nanoparticles was quantified with the use of high content analysis. Data represent the mean \pm the standard error of the mean of three independent experiments performed in triplicate. $* P<0.05$; ${ }^{* * P}<0.01$ as compared with inactivated cells at $0.05 \mathrm{~Pa}$; ${ }^{*} \boldsymbol{P}<0.05$ as compared with TNF- $\alpha$-activated cells at $0.05 \mathrm{~Pa}$.

Abbreviations: QD, quantum dot(s); RFU, Relative fluorescence units; TNF, tumor necrosis factor.

\section{Shear stress induces the}

\section{compartmentalization of nanoparticles} in human endothelial cells

A mild detergent treatment preserves cell viability but increases the membrane penetration capacity of QDs. ${ }^{43}$ However, no previous work has been done to evaluate the optimal concentration of Triton X in live HUVECs to maximize NP uptake. Therefore, cells were exposed to $0.001 \%$, $0.01 \%, 0.1 \%$, or $0.5 \%$ Triton $\mathrm{X}$, and the actin filaments were imaged with the use of confocal microscopy (Figure S2A-E).
Our results suggest that HUVEC could be exposed to a mild detergent concentration of $0.001 \%$ Triton $\mathrm{X}$ for up to 1 hour with negligible cytoskeletal disruption, as shown in Figure S2B.

Confocal images demonstrating the localization of QD2.7, QD4.7, and NP50 in HUVECs after exposure for 20 minutes under static conditions (ie, equivalent to a pressure of $0 \mathrm{~Pa}$ ) and $\mathrm{SS}$ conditions are shown in Figure 4. In live cells, negatively charged QDs (Figure 4A and B) did not show internalization - only low values of 


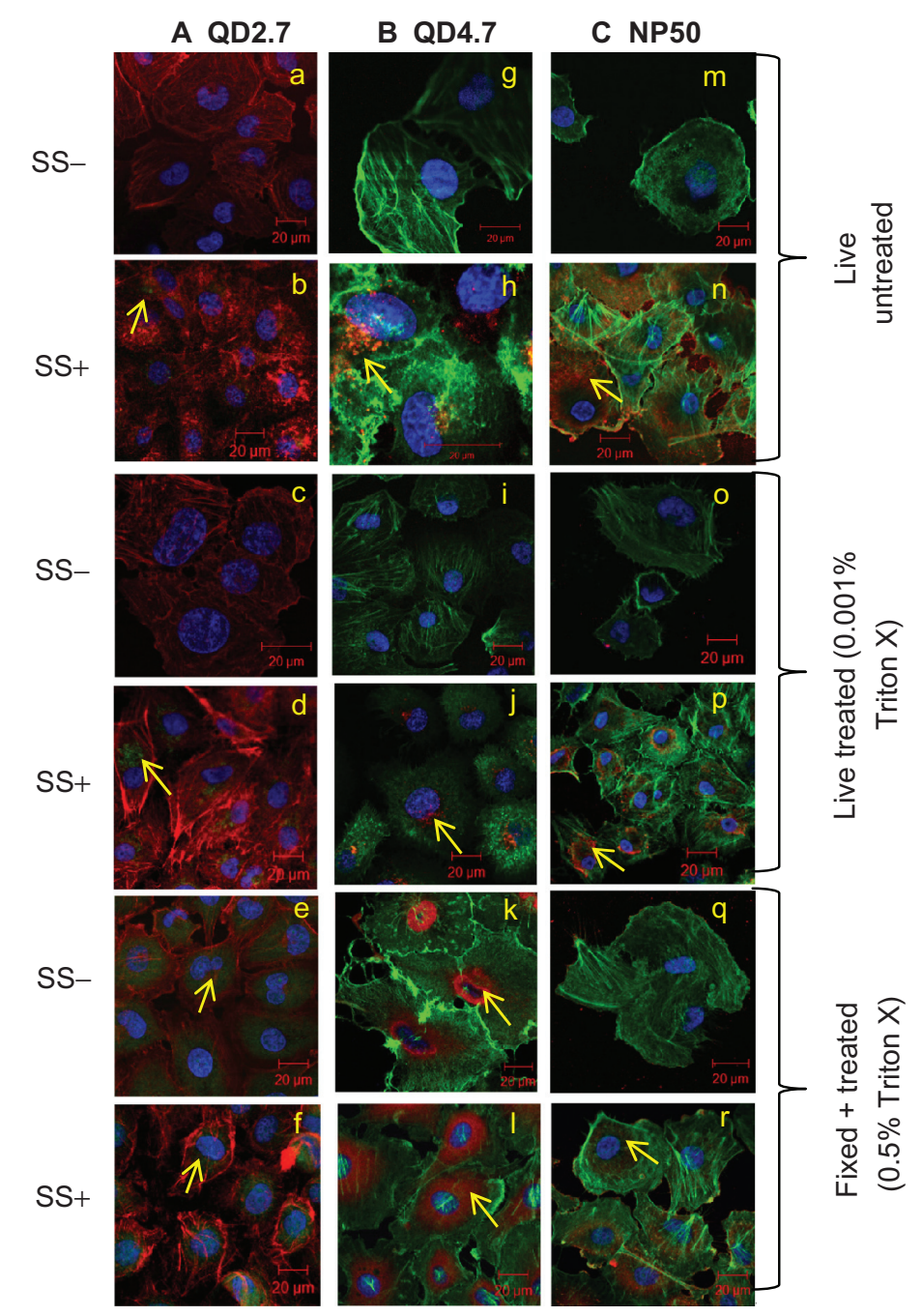

Figure 4 Cellular localization of negatively charged nanoparticles in human umbilical vein endothelial cells (HUVECs). HUVEC monolayers were exposed to (A) QD2.7, (B) QD4.7, and (C) NP50 suspended in phosphate buffered saline under static conditions or at a shear stress (SS) rate of 0.05 Pa for 20 minutes under various conditions as indicated. Samples were then fixed and stained for confocal microscopy studies. The localization of particles in HUVECs exposed (SS+) or not exposed (SS-) to SS was compared. The left panel shows confocal images that demonstrate the compartmentalization of QD2.7 in live untreated (a and b) live treated (c and d), and fixed/ permeabilized (e and $\mathbf{f})$ HUVECs. The middle panel shows confocal images that demonstrate the compartmentalization of QD4.7 in live untreated ( $\mathbf{g}$ and $\mathbf{h}$ ), live treated (i and $\mathbf{j}$ ), and fixed/permeabilized ( $\mathbf{k}$ and $\mathbf{l})$ HUVECs. The right panel shows confocal images that demonstrate the compartmentalization of NP50 in live untreated ( $\mathbf{m}$ and $\mathbf{n}$ ), live treated (o and $\mathbf{p})$, and fixed/permeabilized (q and $\mathbf{r}$ ) HUVECs.

Notes: These images are representative of three independent experiments. The arrows indicate the location of the quantum dots or nanoparticles.

Abbreviation: QD, quantum dot(s).

background fluorescence - under static (ie, 0 Pa) conditions (Figure 4a, c, g, and i), whereas they penetrated the cells under SS conditions (Figure $4 \mathrm{~b}, \mathrm{~d}, \mathrm{~h}$, and j). In the present study, both types of QDs were found localized near the nucleus of live cells (Figure $4 \mathrm{~b}$ and $\mathrm{h}$ ) under SS conditions, but they did not enter the nucleus. The treatment of live cells with detergent (ie, $0.001 \%$ Triton X) did not significantly alter the localization of the QDs (Figure $4 \mathrm{~d}$ and $\mathrm{j}$ ).

In our studies with fixed and permeabilized cells (ie, fixed and treated), the QDs entered the cytoplasm of cells under both static (Figure $4 \mathrm{e}$ and $\mathrm{k}$ ) and SS conditions (Figure 4f and 1). QD2.7 (ie, green-emitting QDs) penetrated the nucleus (Figure 4e), whereas QD4.7 (ie, red-emitting QDs) was concentrated at the perinuclear region (Figure 4k). Z-stack images of QD2.7 and QD4.7 localization in HUVECs are shown in the Supplementary information (Figures S3 and S4).

Negatively charged NP50 (Figure 4C) did not infiltrate into the cytoplasm of both live (Figure $4 \mathrm{~m}$ and o) and fixed/ permeabilized cells (Figure 4q) under static conditions. However, under SS conditions, the particles were bound to the cell membrane in live cells (Figure 4n and p) and localized intracytoplasmically in the fixed/permeabilized cells (Figure 4r). Z-stack images of NP50 localization in HUVECs are shown in the supplementary information (Figure S5). 


\section{Shear stress induces cytoskeletal reorganization in endothelial cells}

The influence of SS on HUVEC morphology was investigated by means of immunofluorescence and AFM. Cultured endothelial monolayers were exposed to an SS of $0.05 \mathrm{~Pa}$ and/or QD for 20 minutes at $37^{\circ} \mathrm{C}$. Cells were then stained with Alexa Fluor ${ }^{\circledR}$ phalloidin that specifically binds to actin. Monolayers of resting ECs showed an elaborate array of microfilament bundles of actin fibers (Figure 5A). SS and QD exposure led to a dramatic change in actin cytoskeleton (ie, a uniform network of phalloidin-stained actin microfilaments), which differed from the actin cables seen in untreated cells (Figure 5B and C, respectively). By contrast, under SS conditions, cytoskeletal reorganization was not observed in cells that were exposed to NP50 (Figure 5D). To strengthen the results of the confocal studies, AFM analysis was carried out. HUVECs that were not subjected to SS showed a flattened morphology with a smooth surface (Figure 5E), whereas their exposure to SS induced the formation of membrane ruffles and stress fibers (Figure 5F and G). Many protrusions appeared extended in different directions, and a dense network was formed mainly around the nucleus.
No such changes were observed in cells that were exposed to NP50 under SS (Figure 5H). The cytoskeletal organization was more prominent in cells that were exposed to both QDs and SS (Figure 5C and $\mathrm{G}$ ) as compared with cells that were exposed to SS alone (Figure 5B and F).

\section{Discussion}

The endothelium is one of the important cellular components of the human vascular microenvironment. It is constantly subjected to hemodynamic SSs that range between 0.05 and $0.76 \mathrm{~Pa}$ in the veins, 0.3 and $0.7 \mathrm{~Pa}$ in the peripheral arteries (eg, the brachial artery, the femoral artery), and 1 and $1.5 \mathrm{~Pa}$ in the central arteries (eg, the carotid artery). In this study, we chose to work in the pressure range between 0.05 and $0.5 \mathrm{~Pa}$, which can be achieved and reliably reproduced with the Cellix microfluidic platform using VenaEC ${ }^{\mathrm{TM}}$ Biochips. This SS range could mimic the physiological SS of postcapillary venules and peripheral arteries. We studied the interaction of negatively charged CdTe-QDs and fluorescent $\mathrm{SiO}_{2}-\mathrm{NPs}$ on a human EC line under static and dynamic conditions (ie, with SS applied). In addition, we also analyzed the changes in the morphology of cells that occurred in response to SS.

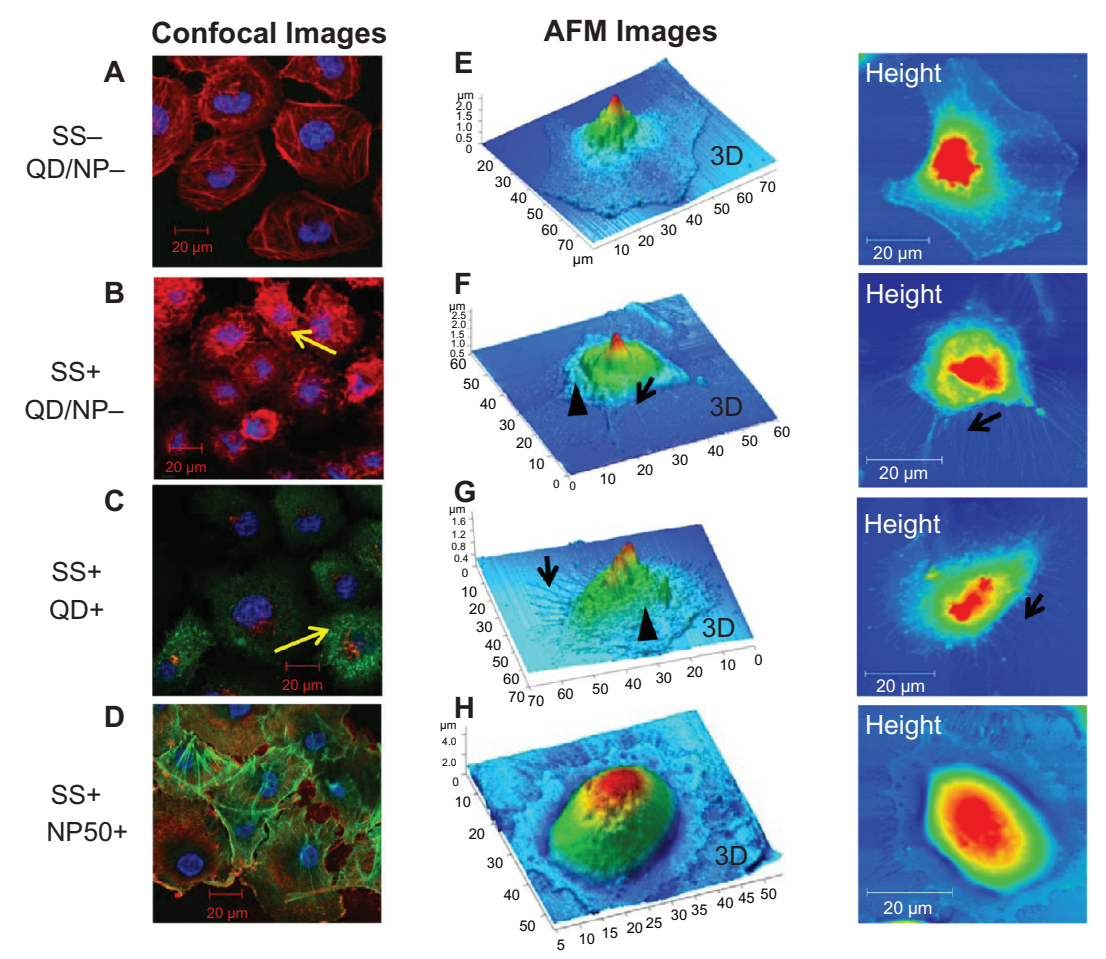

Figure 5 Cytoskeletal reorganization induced by shear stress (SS). Cells were stained (red, actin; blue, nucleus) for confocal analysis while they were fixed with glutaraldehyde and left in PBS for liquid phase atomic force microscopy studies. Images of human umbilical vein endothelial cells (HUVECs) exposed to static (SS-) and shear stress (SS+) conditions are shown. Confocal microscopy images show actin distribution in HUVECs exposed to (A) static conditions, (B) shear stress, (C) quantum dots, and (D) nanoparticles (NP50). Atomic force microscopy (AFM) images show the surface topography of HUVECs exposed to (E) static conditions, (F) shear stress, (G) quantum dots, and (H) nanoparticles (NP50).

Notes: Images are representative of three independent experiments, and they show shear-induced cytoskeletal (actin) reorganization (yellow arrows), membrane ruffling (arrowheads), and stress fibers (black arrows). Cells exposed to NP50 (G and H) did not demonstrate any cytoskeletal reorganization.

Abbreviation: QD, quantum dots. 
The uptake and localization of CdTe-QD2.7, CdTeQD4.7, and $\mathrm{SiO}_{2}-\mathrm{NP} 50$ in $\mathrm{EC}$ were studied over a time period of 20 minutes under static and various SS conditions. We found that neither CdTe-QD nor $\mathrm{SiO}_{2}-\mathrm{NP}$ entered live ECs under static conditions. However, the uptake was found to be maximal at an SS of $0.05 \mathrm{~Pa}$. Furthermore, the activation of cells with TNF- $\alpha$, which simulated an inflamed endothelium, demonstrated no difference with regard to the uptake of NP. This could suggest that the SS-induced NP uptake was independent of the adhesion molecules (ie, selectins E, L, and P; PECAM, VCAM, and ICAM) expressed by activated endothelium, at least for NPs in the size range not exceeding $50 \mathrm{~nm}$, as demonstrated by our study.

It is known that the nuclear pore allows for the passage of biomolecules smaller than $9 \mathrm{~nm}$ by passive diffusion, ${ }^{44}$ whereas active transport is required for molecules of up to approximately $39 \mathrm{~nm} .{ }^{45}$ In the present study, CdTe-QDs were found to be localized near the nucleus of live ECs within 20 minutes of exposure to SS, but they were not inside the nucleus. It could be presumed that the CdTe-QDs are first trapped in endocytic vesicles and then subsequently transported by molecular motors along microtubule tracks to the perinuclear area. This is in agreement with the work of Nabiev and colleagues, who demonstrated that the surface protonation of CdTe-QDs in the endolysosomal compartment - followed by their reversible and $\mathrm{pH}$ dependent aggregation - was responsible for their escape into the cytoplasm. ${ }^{30}$ This phenomenon could also be attributed to the possible interactions of CdTe-QDs with the cytoplasmic proteins, thereby forming a "protein corona" that gave them different biological properties and subsequently determined the fate of CdTe-QD localization.

Observations made in this study also suggest that the exposure of HUVECs to mild detergent treatment using $0.001 \%$ Triton X-100, which increases membrane penetration capacity for NP but preserves cell viability, ${ }^{43}$ did not significantly influence the localization of QDs and NPs in live ECs. However, in experiments with fixed and permeabilized cells, in which cell-membrane-associated uptake mechanisms are eliminated and putative physical subcellular barriers are preserved ${ }^{43}$ the CdTe-QDs were found internalized into the cells under both static and flow conditions. In addition, fixation and permeabilization also ensure that the barriers to particle localization are mainly a function of size. QD4.7 was concentrated at the perinuclear region, which suggests that QDs have strong bonding with the subcellular structures around the nucleus; this is in agreement with previous studies involving the use of QDs on ECs. ${ }^{43}$ By contrast, QD2.7 was found to have accumulated in the cytoplasm and also to have penetrated into the nucleus. These findings indicate that the permeabilization did not affect the ability of particles to enter through the outer cell membrane, whereas the size of the particles determined their passage through the nuclear membrane. The leading mechanism for nuclear localization could be the result of the strong electrostatic attraction of negatively charged CdTe-QDs to positively charged histoneenriched compartments in the nucleus and the nucleolus. ${ }^{46}$ Our findings additionally confirm that the nuclear pore has a size-specific cutoff band of approximately 3.8 to $4.0 \mathrm{~nm}$, even with paralyzed nuclear transport machinery. ${ }^{30}$

We found that negatively charged $\mathrm{SiO}_{2}$-NPs did not infiltrate into the cytoplasm of both live cells (ie, untreated cells and those treated with Triton X) and fixed/permeabilized cells under static conditions. However, under the influence of SS, the $\mathrm{SiO}_{2}-\mathrm{NPs}$ were bound to the cell membrane in live cells and confined to the cytoplasm in fixed/permeabilized cells. This suggests that the fixation/permeabilization of the cell membrane and a mechanical (shear) force are needed to infiltrate the cytoplasm for fluorescent-tagged $\mathrm{SiO}_{2}-\mathrm{NPs}$. The observed inability of the $\mathrm{SiO}_{2}-\mathrm{NPs}$ to penetrate the live plasma membrane - despite the applied SS - could be attributed to their large size. However, previous studies performed with BSA-coated polymeric NPs on ECs have demonstrated that caveolae could accommodate particles of up to $100 \mathrm{~nm}$; this is larger than the typical caveolar diameter, which suggests that these organelles have adaptable properties. ${ }^{47}$

The cytoskeletal and topographic changes of untreated HUVECs in response to SS were analyzed by confocal microscopy and AFM. In our studies, membrane ruffling and the endocytosis of CdTe-QDs were detected exclusively in cells that had been exposed to SS. The formation of EC membrane ruffles reflects the process of the transduction of mechanical forces through the cytoskeleton. ${ }^{48}$ Stress-fiber formation demonstrated by AFM in SS-exposed cells could represent a functionally important mechanism that protects the endothelium from hydrodynamic injury. ${ }^{49}$ On the basis of our findings, it could also be suggested that SS-induced membrane ruffles help with the endocytosis of CdTe-QDs.

Finally, the proliferation assay demonstrated that the $\mathrm{SiO}_{2}$-NPs were not toxic to the ECs, whereas CdTe-QDs caused a significant decrease in the cell count. QDs induce the generation of reactive oxygen species, ${ }^{50}$ which leads to detrimental autophagic cell death or necrosis ${ }^{51-53}$ or which activates intrinsic mitochondrial apoptotic pathways. ${ }^{21}$ It is known that smaller QDs penetrate deeper into cells and induce toxicity at far quicker rates than their larger counterparts. ${ }^{54}$ 
However, in our studies, QD4.7 was found to be comparatively more cytotoxic than QD2.7, which could be attributed to either the higher negative charge on the surface or to their preferential accumulation in the cytoplasm, thereby triggering different or additional toxicity mechanisms.

We are therefore able to demonstrate for the first time that $\mathrm{SS}$ is critical for the uptake of CdTe-QD and $\mathrm{SiO}_{2}-\mathrm{NP}$ in $\mathrm{EC}$. Our findings suggest that membrane ruffles formation facilitates the endocytosis of CdTe-QD. Localization of smaller CdTe-QD in the nucleus confirms the presence of active transport processes at the level of nuclear pores in live EC.

The overall message of the present study is that the combinatorial influence of factors such as NP surface characteristics, the presence or absence of SS, and the functional state and cytoskeletal rearrangements of the ECs determine the ultimate fate of the localized NP accumulation, which could have direct consequences for parenterally administered nanoconjugated drugs. For example, prospective nanocarriers could be used for localized drug delivery to the vascular compartments with known SSs within (eg, to the postcapillary venules and veins, with $\mathrm{SS}$ of $0.05 \mathrm{~Pa}$ ). In addition, the possibility of coadministering vasoactive drugs to reduce SS in the vascular compartments could facilitate the uptake of NPs for selective delivery to the inflammatory sites.

\section{Acknowledgments}

We are grateful to Drs Jennifer Conroy, Navin K Verma, and Anthony Davies and to Mr Connla Edwards for helpful discussions and technical help. This work was partially supported by the Higher Education Authority of Ireland, EU FP7 project NAMDIATREAM (contract ref. no 246479), and MULTIFUN (contract ref. no 262943) and Science Foundation Ireland - SRC Bionanointeract.

\section{Disclosure}

The authors report no conflicts of interest in this work.

\section{References}

1. Ando J, Yamamoto K. Effects of shear stress and stretch on endothelial function. Antioxid Redox Signal. 2011;15(5):1389-1403.

2. Ando J, Yamamoto K. Vascular mechanobiology: endothelial cell responses to fluid shear stress. Circ J. 2009;73(11):1983-1992.

3. Girard PR, Nerem RM. Shear stress modulates endothelial cell morphology and F-actin organization through the regulation of focal adhesionassociated proteins. J Cell Physiol. 1995;163(1):179-193.

4. Langille BL, Graham JJ, Kim D, Gotlieb AI. Dynamics of shear-induced redistribution of F-actin in endothelial cells in vivo. Arterioscler Thromb. 1991;11(6): 1814-1820.

5. Malek AM, Izumo S. Mechanism of endothelial cell shape change and cytoskeletal remodeling in response to fluid shear stress. $J$ Cell Sci. 1996;109(Pt 4):713-726.
6. Sato M, Levesque MJ, Nerem RM. Micropipette aspiration of cultured bovine aortic endothelial cells exposed to shear stress. Arteriosclerosis. 1987;7(3):276-286.

7. Imberti B, Morigi M, Zoja C, et al. Shear stress-induced cytoskeleton rearrangement mediates NF-kappaB-dependent endothelial expression of ICAM-1. Microvasc Res. 2000;60(2):182-188.

8. Kakisis JD, Liapis CD, Sumpio BE. Effects of cyclic strain on vascular cells. Endothelium. 2004;11(1):17-28.

9. Resnick N, Collins T, Atkinson W, Bonthron DT, Dewey CF Jr, Gimbrone MA Jr. Platelet-derived growth factor B chain promoter contains a cis-acting fluid shear-stress-responsive element. Proc Natl Acad Sci U SA. 1993;90(10):4591-4595.

10. LittlerAJ, Buckley CD, Wordsworth P, Collins I, Martinson J, Simmons DL. A distinct profile of six soluble adhesion molecules (ICAM-1, ICAM-3, VCAM-1, E-selectin, L-selectin and P-selectin) in rheumatoid arthritis. Rheumatology. 1997;36(2):164-169.

11. Lin A, Sabnis A, Kona S, et al. Shear-regulated uptake of nanoparticles by endothelial cells and development of endothelial-targeting nanoparticles. J Biomed Mater Res A. 2010;93(3):833-842.

12. Omolola Eniola A, Hammer DA. In vitro characterization of leukocyte mimetic for targeting therapeutics to the endothelium using two receptors. Biomaterials. 2005;26(34):7136-7144.

13. Traub O, Berk BC. Laminar shear stress: mechanisms by which endothelial cells transduce an atheroprotective force. Arterioscler Thromb Vasc Biol. 1998;18(5):677-685.

14. Kroll MH, Hellums JD, McIntire LV, Schafer AI, Moake JL. Platelets and shear stress. Blood. 1996;88(5):1525-1541.

15. Reneman RS, Arts T, Hoeks AP. Wall shear stress - an important determinant of endothelial cell function and structure - in the arterial system in vivo. Discrepancies with theory. J Vasc Res. 2006;43(3):251-269.

16. Reneman RS, Hoeks AP. Wall shear stress as measured in vivo: consequences for the design of the arterial system. Med Biol Eng Comput. 2008;46(5):499-507.

17. Stroev PV, Hoskins PR, Easson WJ. Distribution of wall shear rate throughout the arterial tree: a case study. Atherosclerosis. 2007;191(2):276-280.

18. Wu SP, Ringgaard S, Oyre S, Hansen MS, Rasmus S, Pedersen EM. Wall shear rates differ between the normal carotid, femoral, and brachial arteries: an in vivo MRI study. J Magn Reson Imaging. 2004;19(2):188-193.

19. Davda J, Labhasetwar V. Characterization of nanoparticle uptake by endothelial cells. Int J Pharm. 2002;233(1-2):51-59.

20. Cherian AK, Rana AC, Jain SK. Self-assembled carbohydrate-stabilized ceramic nanoparticles for the parenteral delivery of insulin. Drug Dev Ind Pharm. 2000;26(4):459-463.

21. Yan M, Zhang Y, Xu K, Fu T, Qin H, Zheng X. An in vitro study of vascular endothelial toxicity of CdTe quantum dots. Toxicology. 2011;282(3):94-103.

22. Resch-Genger U, Grabolle M, Cavaliere-Jaricot S, Nitschke R, Nann T. Quantum dots versus organic dyes as fluorescent labels. Nat Methods. 2008;5(9):763-775.

23. Bagalkot V, Zhang L, Levy-Nissenbaum E, et al. Quantum dot-aptamer conjugates for synchronous cancer imaging, therapy, and sensing of drug delivery based on bi-fluorescence resonance energy transfer. Nano Lett. 2007;7(10):3065-3070.

24. Manabe N, Hoshino A, Liang YQ, Goto T, Kato N, Yamamoto K. Quantum dot as a drug tracer in vivo. IEEE Trans Nanobioscience. 2006;5(4):263-267.

25. Weng J, Ren J. Luminescent quantum dots: a very attractive and promising tool in biomedicine. Curr Med Chem. 2006;13(8):897-909.

26. Jaiswal JK, Mattoussi H, Mauro JM, Simon SM. Long-term multiple color imaging of live cells using quantum dot bioconjugates. Nat Biotechnol. 2003;21(1):47-51.

27. Duan H, Nie S. Cell-penetrating quantum dots based on multivalent and endosome-disrupting surface coatings. J Am Chem Soc. 2007;129(11):3333-3338. 
28. Knight VB, Serrano EE. Tissue and species differences in the application of quantum dots as probes for biomolecular targets in the inner ear and kidney. IEEE Trans Nanobioscience. 2006;5(4):251-262.

29. Ryman-Rasmussen JP, Riviere JE, Monteiro-Riviere NA. Surface coatings determine cytotoxicity and irritation potential of quantum dot nanoparticles in epidermal keratinocytes. J Invest Dermatol. 2007;127(1):143-153.

30. Nabiev I, Mitchell S, Davies A, et al. Nonfunctionalized nanocrystals can exploit a cell's active transport machinery delivering them to specific nuclear and cytoplasmic compartments. Nano Lett. 2007;7(11):3452-3461.

31. Yamawaki H, Iwai N. Mechanisms underlying nano-sized air-pollutionmediated progression of atherosclerosis: carbon black causes cytotoxic injury/inflammation and inhibits cell growth in vascular endothelial cells. Circ J. 2006;70(1):129-140.

32. Rosas-Hernández H, Jiménez-Badillo S, Martínez-Cuevas PP, et al. Effects of 45-nm silver nanoparticles on coronary endothelial cells and isolated rat aortic rings. Toxicol Lett. 2009;191(2-3):305-313.

33. Gojova A, Guo B, Kota RS, Rutledge JC, Kennedy IM, Barakat AI. Induction of inflammation in vascular endothelial cells by metal oxide nanoparticles: effect of particle composition. Environ Health Perspect. 2007;115(3):403-409.

34. Ge S, Wang G, Shen Y, et al. Cytotoxic effects of MgO nanoparticles on human umbilical vein endothelial cells in vitro. IET Nanobiotechnol. 2011;5(2):36.

35. Napierska D, Thomassen LC, Rabolli V, et al. Size-dependent cytotoxicity of monodisperse silica nanoparticles in human endothelial cells. Small. 2009;5(7):846-853.

36. Byrne SJ, Corr SA, Rakovich TY, et al. Optimisation of the synthesis and modification of CdTe quantum dots for enhanced live cell imaging. J Mater Chem. 2006;16(28):2896-2902.

37. Choi EY, Chavakis E, Czabanka MA, et al. Del-1, an endogenous leukocyte-endothelial adhesion inhibitor, limits inflammatory cell recruitment. Science. 2008;322(5904):1101-1104

38. Demyanets S, Konya V, Kastl SP, et al. Interleukin-33 induces expression of adhesion molecules and inflammatory activation in human endothelial cells and in human atherosclerotic plaques. Arterioscler Thromb Vasc Biol. 2011;31(9):2080-2089.

39. Philipose S, Konya V, Sreckovic I, et al. The prostaglandin E2 receptor EP4 is expressed by human platelets and potently inhibits platelet aggregation and thrombus formation. Arterioscler Thromb Vasc Biol. 2010;30(12):2416-2423.

40. Robinson AJ, Kashanin D, O’Dowd F, Williams V, Walsh GM. Montelukast inhibition of resting and GM-CSF-stimulated eosinophil adhesion to VCAM-1 under flow conditions appears independent of cysLT(1)R antagonism. J Leukoc Biol. 2008;83(6):1522-1529.
41. Mohamed BM, Verma NK, Prina-Mello A, et al. Activation of stressrelated signalling pathway in human cells upon $\mathrm{SiO} 2$ nanoparticles exposure as an early indicator of cytotoxicity. $J$ Nanobiotechnology. 2011;9:29.

42. Nan A, Bai X, Son SJ, Lee SB, Ghandehari H. Cellular uptake and cytotoxicity of silica nanotubes. Nano Lett. 2008;8(8):2150-2154.

43. Williams Y, Sukhanova A, Nowostawska M, et al. Probing cell-typespecific intracellular nanoscale barriers using size-tuned quantum dots. Small. 2009;5(22):2581-2588.

44. Choi HS, Liu W, Misra P, et al. Renal clearance of quantum dots. Nat Biotechnol. 2007;25(10):1165-1170.

45. Pante N, Kann M. Nuclear pore complex is able to transport macromolecules with diameters of about $39 \mathrm{~nm}$. Mol Biol Cell. 2002;13(2):425-434.

46. Conroy J, Byrne SJ, Gun'ko YK, et al. CdTe nanoparticles display tropism to core histones and histone-rich cell organelles. Small. 2008;4(11):2006-2015.

47. Wang Z, Tiruppathi C, Minshall RD, Malik AB. Size and dynamics of caveolae studied using nanoparticles in living endothelial cells. ACS Nano. 2009;3(12):4110-4116.

48. Ishida T, Takahashi M, Corson MA, Berk BC. Fluid shear stress-mediated signal transduction: how do endothelial cells transduce mechanical force into biological responses? Ann N Y Acad Sci. 1997;811:12-23; discussion 23-24.

49. Wong AJ, Pollard TD, Herman IM. Actin filament stress fibers in vascular endothelial cells in vivo. Science. 1983;219(4586):867-869.

50. Samia AC, Chen X, Burda C. Semiconductor quantum dots for photodynamic therapy. J Am Chem Soc. 2003;125(51):15736-15737.

51. Liu X, Sun J. Endothelial cells dysfunction induced by silica nanoparticles through oxidative stress via JNK/P53 and NF-kappaB pathways. Biomaterials. 2010;31(32):8198-8209.

52. Stern ST, Zolnik BS, McLeland CB, Clogston J, Zheng J, McNeil SE. Induction of autophagy in porcine kidney cells by quantum dots: a common cellular response to nanomaterials? Toxicol Sci. 2008;106(1):140-152.

53. Yamawaki H, Iwai N. Cytotoxicity of water-soluble fullerene in vascular endothelial cells. Am J Physiol Cell Physiol. 2006;290(6): C1495-C1502.

54. Prasad BR, Nikolskaya N, Connolly D, et al. Long-term exposure of CdTe quantum dots on PC12 cellular activity and the determination of optimum non-toxic concentrations for biological use. J Nanobiotechnology. 2010;8:7 


\section{Supplementary figures}

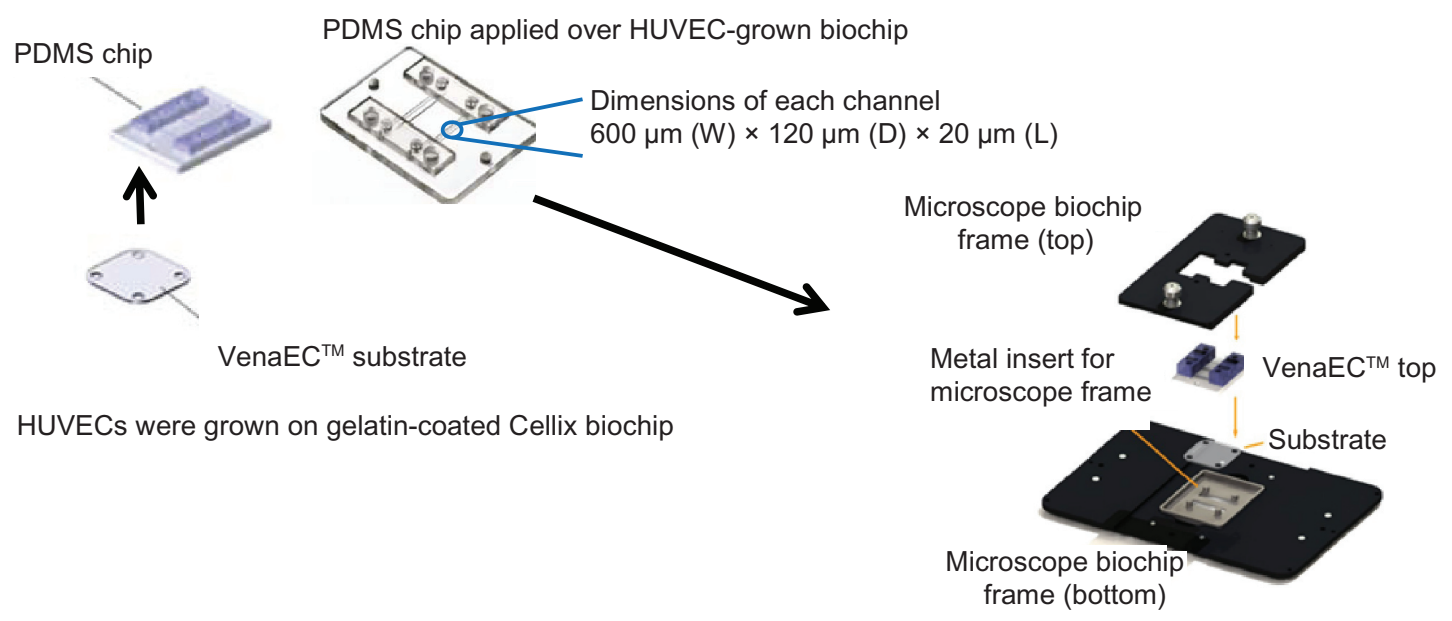

Figure SI Regulated shear stress assays - VenaEC ${ }^{\mathrm{TM}}$ Biochip protocol: Image explains assembly of $\mathrm{HUVEC}$-grown substrate for CdTe-QD and $\mathrm{SiO}_{2}-\mathrm{NP}$ uptake assays under regulated flow conditions.

Abbreviations: QD, quantum dot(s); NP, nanoparticle(s); HUVEC(s), human umbilical vein endothelial cell(s); EC, endothelial cell(s); SS, shear stress; PDMS, polydimethylsiloxane.
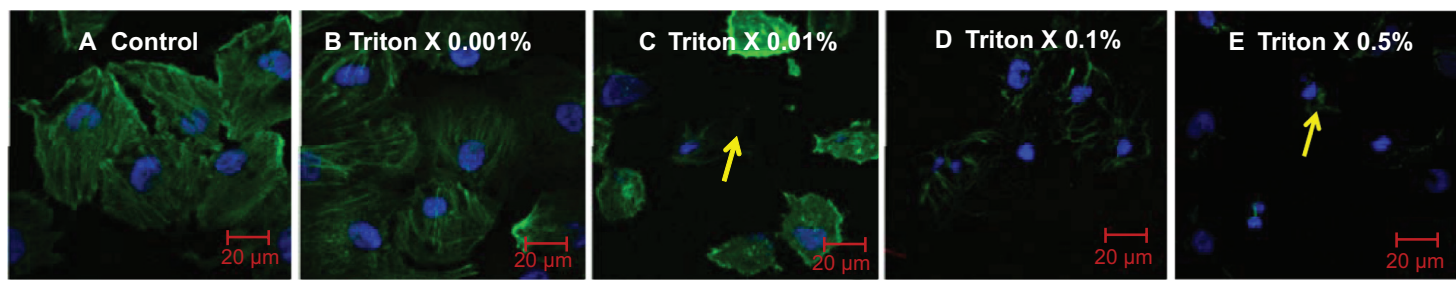

Figure S2 Effect of Triton $X$ detergent concentrion range (0, 0.00I, 0.0I, 0.1 and $0.5 \%)$ on live HUVEC actin-cytoskeletal filaments: HUVECs were grown on 8 chamber slides. After $24 \mathrm{~h}$, cells $(\mathbf{A})$ were treated with $0.001 \%$ (B), $0.01 \%$ (C), $0.1 \%$ (D) or $0.5 \%$ (E) Triton $\mathrm{X}$ in cell culture medium for I $\mathrm{h}$ at $37^{\circ} \mathrm{C}$.

Notes: Cells not treated with Triton $\mathrm{X}$ were taken as control. After staining (actin-red, nucleus-blue) the chambers were removed, cells were covered with a glass cover slip using mounting medium and left at $4^{\circ} \mathrm{C}$ overnight. Confocal images (maximal projection) are shown. Images are representative of three independent experiments. Arrows point to the areas with disorganized actin.

Abbreviations: NP, nanoparticle(s); HUVEC(s), human umbilical vein endothelial cell(s); EC, endothelial cell(s); SS, shear stress. 


\section{A}

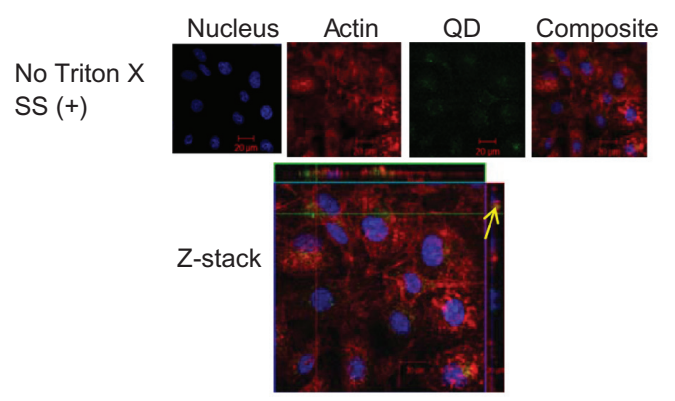

C

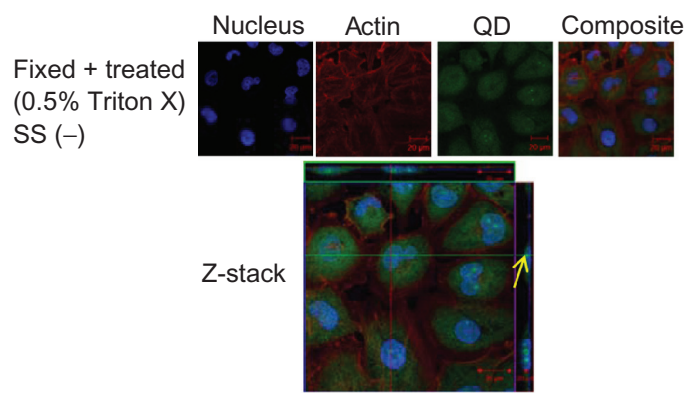

B

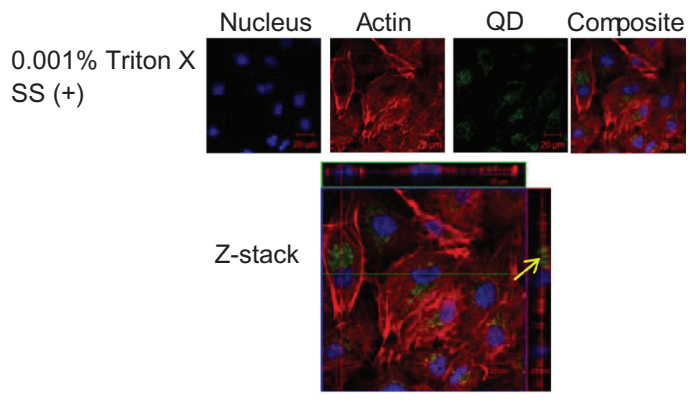

D

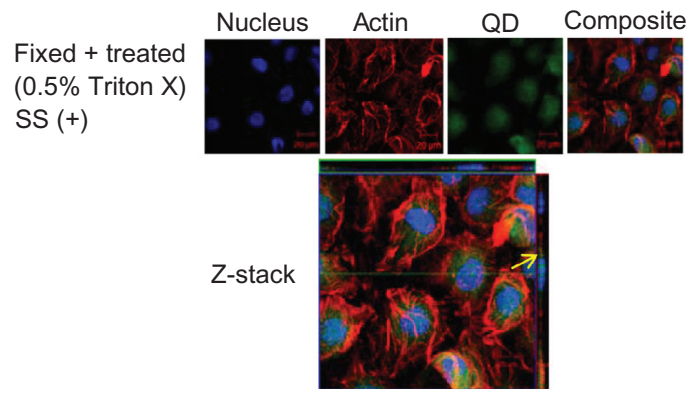

Figure S3 Localization of negatively charged $2.7 \mathrm{~nm}$ CdTe-QD in HUVECs. HUVECs were exposed to QD under various conditions. Z-stack (single slice) images of HUVECs showing localization of QD in the following conditions. (A) Z-stack showing intra-cytoplasmic localization of QD in untreated cells under shear stress conditions (0.05 Pa); (B) Z-stack showing intra-cytoplasmic localization of QD in cells which are treated with $0.001 \%$ Triton $\mathrm{X}$ and exposed to QD under shear stress conditions ( 0.05 $\mathrm{Pa})$; (C) Z-stack showing both intra-cytoplasmic and intra-nuclear localization of QD in fixed/permeabilized cells under static conditions; (D) Z-stack showing both intracytoplasmic and intra-nuclear localization of QD in fixed/permeabilized cells under shear stress conditions $(0.05 \mathrm{~Pa})$.

Notes: Images are representative of three independent experiments. Arrows: location of $2.7 \mathrm{~nm}$ QD.

Abbreviations: QD, quantum dot(s); NP, nanoparticle(s); HUVEC(s), human umbilical vein endothelial cell(s); EC, endothelial cell(s); SS, shear stress.

A

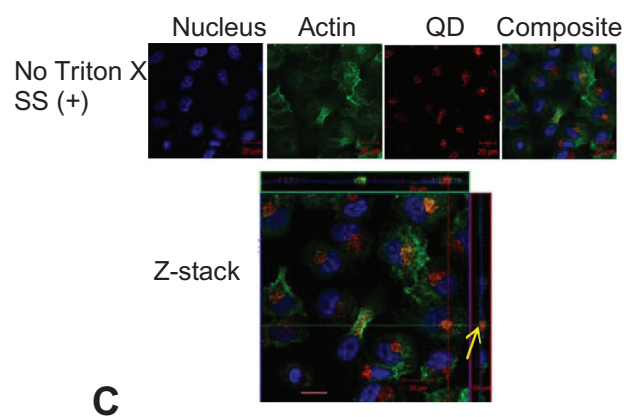

Nucleus Actin QD Composite

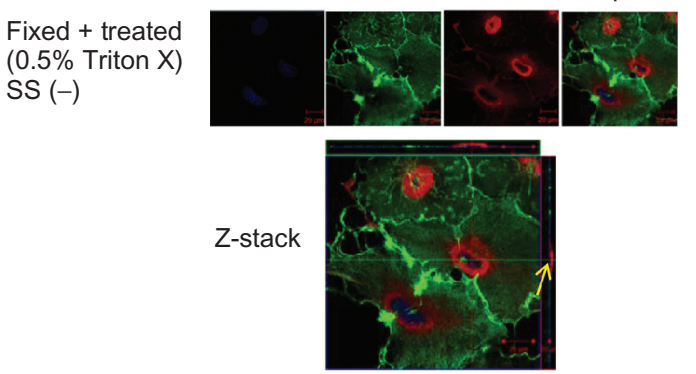

B

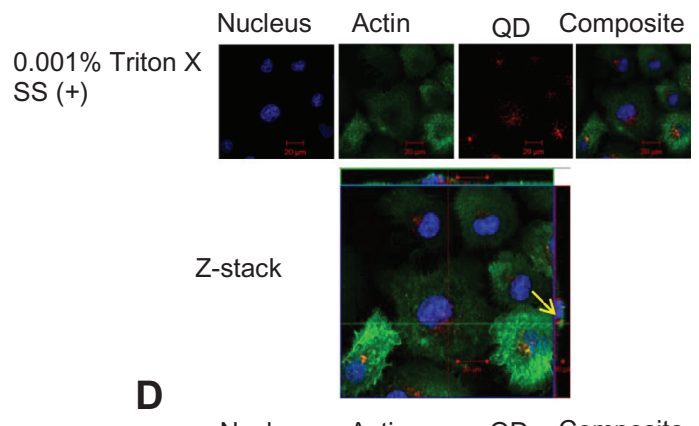

Nucleus Actin QD Composite

Fixed + treated $(0.5 \%$ Triton $\mathrm{X})$ SS (+)

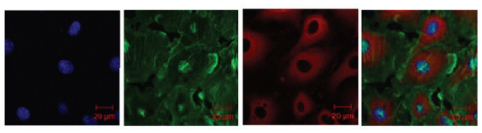

Z-stack

Figure S4 Localization of negatively charged $4.7 \mathrm{~nm}$ CdTe-QD in HUVECs. HUVECs were exposed to QD under various conditions. Z-stack (single slice) images of HUVECs showing localization of QD in the following conditions. (A) Z-stack showing intra-cytoplasmic localization of QD in untreated cells under shear stress conditions ( 0.05 Pa); (B) Z-stack showing intra-cytoplasmic localization of QD in cells which are treated with $0.001 \%$ Triton $\mathrm{X}$ and exposed to QD under shear stress conditions ( 0.05 Pa); (C) Z-stack showing perinuclear localization of QD in fixed/permeabilized cells under static conditions; (D) Z-stack showing intra-cytoplasmic localization of QD in fixed/ permeabilized cells under shear stress conditions $(0.05 \mathrm{~Pa})$.

Notes: Images are representative of three independent experiments. Arrows: location of $4.7 \mathrm{~nm}$ QD.

Abbreviations: QD, quantum dot(s); NP, nanoparticle(s); HUVEC(s), human umbilical vein endothelial cell(s); EC, endothelial cell(s); SS, shear stress. 
A
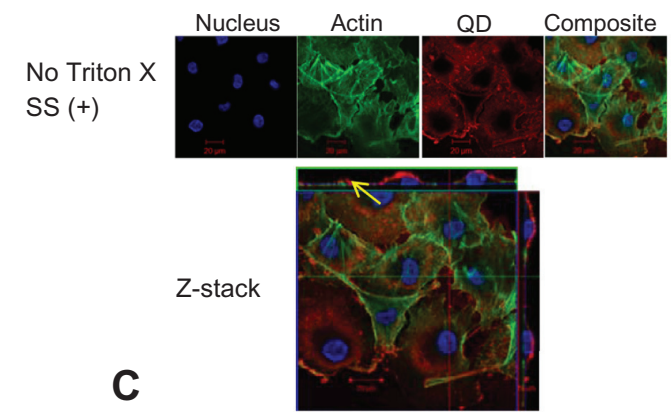

C

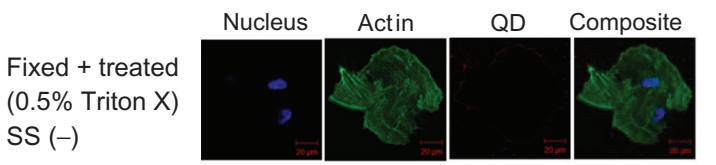

Z-stack

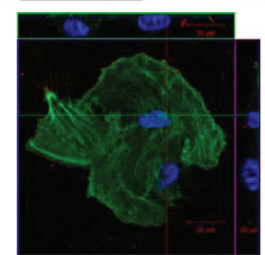

B

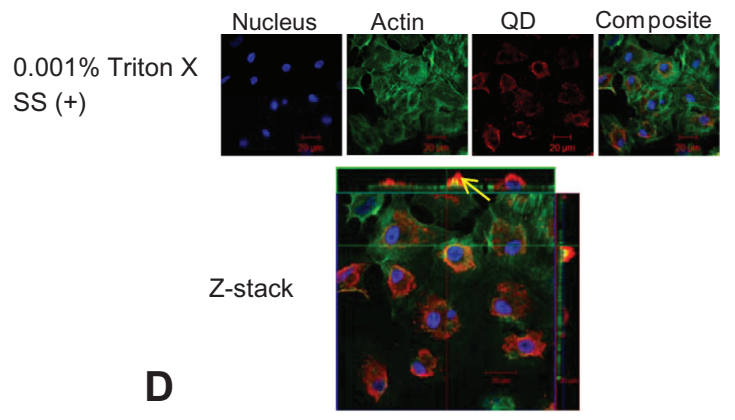

Fixed + treated
$(0.5 \%$ Triton X)
SS (+)

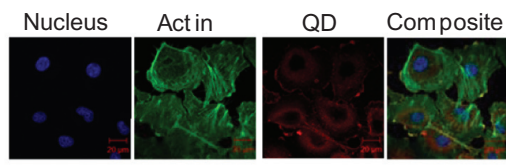

Z-stack

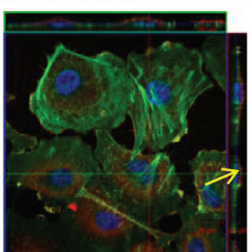

Figure S5 Localization of negatively charged $50 \mathrm{~nm}$ fluorescent $\mathrm{SiO}_{2}$-NP in HUVECs. HUVECs were exposed to $\mathrm{SiO}_{2}-\mathrm{NP}$ under various conditions. Z-stack (single slice) images show localization of NP under the following conditions. (A) Z-stack showing surface localization of $\mathrm{SiO}_{2}-\mathrm{NP}_{\text {in }}$ untreated cells under shear stress conditions ( 0.05 $\mathrm{Pa})$; (B) Z-stack showing surface localization of $\mathrm{SiO}_{2}-\mathrm{NP}$ in cells which were treated with $0.001 \%$ Triton $\mathrm{X}$ under flow conditions $(0.05 \mathrm{~Pa})$; (C) Z-stack showing absence of $\mathrm{NP}$ association in fixed/permeabilized cells under static conditions; (D) Z-stack showing intra-cytoplasmic localization of $\mathrm{SiO}_{2}-\mathrm{NP}$ in in fixed/permeabilized cells under shear stress conditions $(0.05 \mathrm{~Pa})$.

Notes: Images are representative of three independent experiments. Arrows: location of $50 \mathrm{~nm}$ silica NP.

Abbreviations: QD, quantum $\operatorname{dot}(\mathrm{s})$; NP, nanoparticle(s); HUVEC(s), human umbilical vein endothelial cell(s); EC, endothelial cell(s); SS, shear stress.

\section{Publish your work in this journal}

The International Journal of Nanomedicine is an international, peerreviewed journal focusing on the application of nanotechnology in diagnostics, therapeutics, and drug delivery systems throughout the biomedical field. This journal is indexed on PubMed Central, MedLine, CAS, SciSearch $\AA$, Current Contents $₫ /$ Clinical Medicine,
Journal Citation Reports/Science Edition, EMBase, Scopus and the Elsevier Bibliographic databases. The manuscript management system is completely online and includes a very quick and fair peer-review system, which is all easy to use. Visit http://www.dovepress.com/ testimonials.php to read real quotes from published authors. 